\title{
Traduzindo Ferro para a Nova Área de Estudos da Produção: Uma colaboração entre Reino Unido e Brasil
}

Translating Ferro for the New Field of Production Studies: A UK / Brazil collaboration

Katie Lloyd Thomas*

*Professora de Teoria e História da Arquitetura na Universidade de Newcastle e editora do Architectural Research Quarterly. Ela é pesquisadora principal no Reino Unido do projeto AHRC financiado pela FAPESP Translating Ferro / Transforming Knowledges (2020-2024), katie.lloyd-thomas@ncl.ac.uk

\section{Palavras-chave:}

Sérgio Ferro,

Estudos da Produção

construção.

\section{Keywords:}

Sérgio Ferro,

Production Studies,

building labour.

\section{Resumo}

Este artigo rastreia o surgimento e trajetória de uma colaboração de três anos e meio entre o Reino Unido e Brasil, um projeto chamado "Traduzindo Ferro / Transformando Conhecimentos de Arquitetura, Design e Trabalho para Estudos da Nova Área de Produção (TF/TK)" inaugurada em primeiro de Outubro de 2020. O projeto destaca o crescente interesse no trabalho de Sérgio Ferro em arquitetura e mão-deobra em países cujo idioma é o Inglês, e estabelece como isso a base para uma nova e muito necessária interdisciplinaridade e interculturalidade no campo dos Estudos da Produção. O principal objetivo dessa nova área é desafiar a cegueira da arquitetura direcionada à produção, e entender e interrogar o design e a construção através de contextos culturais.

\section{Abstract}

This article traces the emergence and trajectory of a new UK / Brazil 3.5 year collaborative project Translating Ferro / Transforming Knowledges of Architecture, Design and Labour for the New Field of Production Studies (TF/TK) launching 01 October 2020. It outlines the growing interest in Sérgio Ferro's work on architecture and labour in the Englishspeaking context, and sets out how it will provide the basis for a new and much-needed cross-disciplinary, cross-cultural field of Production Studies. The key objective of this new field is to challenge architecture's blindness to production, and understand and interrogate design and construction across cultural contexts. 


\section{Traduzindo Ferro para a Nova Área de Estudos da Produção: Uma cola-} boração entre Reino Unido e Brasil

Em Novembro de 2014, os historiadores da arquitetura britânicos Tilo Amhoff, Nick Beech e eu mesmo organizamos uma conferência internacional chamada Indústrias da Arquitetura (IOA), na Universidade de Newcastle, com a intenção de colocar a produção no centro do debate das humanidades arquitetônicas. 'Com frequência demais', nós escrevemos em nossa Chamada de Artigos, 'teóricos de arquitetura, historiadores e designers deixam de lado os contextos industriais, técnicos e socioeconômicos, nos quais um edifício é constituído ou sua manutenção não recebem a devida atenção na Arquitetura, mesmo quando reconhecem os limites e possibilidades estabelecidas para a produção arquitetônica na era do capitalismo avançado"1. Dois anos antes, Nick e eu, por meio de um encontro que aconteceu por acaso com um grupo de pesquisadores brasileiros, no encerramento do Quarto Congresso Internacional de História da Construção em Paris ${ }^{2}$, fomos apresentados para o que, mais tarde, iríamos entender como o único e mais exclusivo inquérito em design da perspectiva de mão-de-obra e local de construção disponível em qualquer idioma, aquele realizado por Sérgio Ferro. A tendência do discurso arquitetônico é negligenciar o processo de produção (em detrimento das novas tecnologias, uso, estética, simbolismo, e entre outros), o que IOA problematizou, e é demonstrado por Ferro como mais do que uma questão de falta de abrangência. É uma necessidade estrutural para a manutenção da capacidade da profissão de agir 'sobre' o local de construção em serviço do capital financeiro.

Apesar do status de exclusividade do trabalho de Ferro e seu potencial abrangente de informar entendimentos das relações de produção e arquitetura, e endereçar a atual crise mundial na indústria de construção, não havia, naquele período, traduções dos textos de Ferro para o Inglês, e somente escassas considerações estavam disponíveis sobre as contribuições dele como teórico e historiador, e,

${ }^{1}$ Para detalhes da Chamada de Artigos e o evento, veja www.industriesofarchitecture.org (acesso em 04.08.2020)

${ }^{2} \mathrm{O}$ Quarto Congresso Internacional da História da Construção aconteceu em Paris, entre os dias três e sete de Julho. A título de conferência, veja Robert Carvais, André Guillerme, Valérie Neègre e Joël Sakarovitch (eds.) Nuts \& Bolts of Construction History: Vols.1-3 (Paris: Picard, 2013). O grupo de pesquisadores incluiu Felipe Contier, Silke Kapp, Roberto Eustáquio dos Santos, Carol Heldt, Renato Anelli, Ana Paula Koury. como arquiteto, com a Arquitetura Nova ${ }^{3}$. Nós estávamos convencidos que os argumentos dele estabeleceriam a direção dos debates na conferência IOA, e, com a ajuda de Felipe Contier, Ferro aceitou nosso convite para fazer as considerações iniciais, a qual ele escreveu em Português como uma introdução para Dessin/Chantier'. Apesar de Ferro não conseguir comparecer, nós, mesmo assim, inauguramos o evento com a fala dele - revertendo o planejado formato, no qual uma tradução em Inglês, por Ricardo Agarez, teria sido projetada junto com o Português falado ${ }^{5}$. $O$ argumento contundente de Ferro que defendia o design como uma das maneiras do capital financeiro para decretar seu objetivo final 'de extrair uma quantia substancial de mais-valia', e que os arquitetos 'sejam quais foram as intenções do profissional e quando agir dentro das condições da profissão, estão a serviço do capital' era desconhecido para a maioria dos participantes, porém era difícil e inevitável, e estabeleceu o ritmo para as discussões que se seguiram. Além disso, a inclusão dele na conferência IOA também atraiu um número significativo de pesquisadores brasileiros, que já estavam estudando ou eram informados sobre o trabalho de Ferro. Com Silke Kapp (UFMG) e João Marcos de Almeida Lopes (USP), ambos estudiosos do trabalho de Ferro que basearam seus próprios estudos e grupos (MOM and Usina CTAH) na análise do autor e a possibilidade que ele abre para modos alternativos para construir. Nossas conversas logo resultaram na conclusão de que há a necessidade de traduzir seus

${ }^{3}$ Para boas (mas breves) discussões em Inglês das contribuições teóricas de Ferro, veja MOM (Morar de Outras Maneiras): Silke Kapp, Ana Paula Baltazar, Denise Morado, 'Architecture as Critical Exercise: Little Pointers Towards Alternative Practices' in Field Journal Vol.2 (1) 2016; Jose T. Lira, 'Architectural Criticism and radicalism in Brazil' in Wolfgang F. E. Preiser, Aaaron T. Davis, Ashraf M. Salama and Andrea Hardy (eds.) Architecture Beyond Criticism: Expert judgement and performance evaluation (Londres: Routledge, 2015) e a entrada de Ferro no website da Spatial performance evaluation (Londres: Routledge, 2015) e a entrada de Ferro no website da Spatial Agency: https://www.spatialagency.net/database/sergio.ferro (acesso 07.08.2020). Acerca da Arquitetura Nova veja, Pedro Arantes, 'Reinventing the Building Site', em Brazil's Modern Architecture, eds. Elisabetta Andreoli e Adrian Forty (Londres: Phaidon, 2004), 170-210, e também Rich-
ard J. Williams, Brazil: Modern architectures in history (Londres: Reaktion, 2009).

${ }^{4}$ Foi a versão revisada posteriormente de $\mathrm{O}$ canteiro e o desenho (São Paulo: Projeto Editori Associatos, 1776, 1982), publicada em francês como Dessin / Chantier (Paris: Éditions de la Villette, 2005), que eu consegui ler. O título capturou bem para o nosso público a ideia de Ferro de que, dentro da disciplina, a construção é concebida como se estivesse abaixo da arquitetura e mantém o duplo significado de desenho e design que, de outra forma, se perde na tradução direta como "design". Continuamos a usar a formulação francesa.

${ }^{5} \mathrm{O}$ artigo de Ferro foi publicado como 'Dessin/Chantier: An introduction' (tradução de Ricardo Agarez e Silke Kapp), com 'Uma introdução em Sérgio Ferro' por Felipe Contier na série Critiques, Katie Lloyd Thomas, Tilo Amhoff e Nick Beech (eds.), Industries of Architecture (Londres: Routled ge, 2015). 
trabalhos principais em Inglês. Silke e eu visitamos Ferro na casa dele, em Grignan, na França, em Novembro de 2014, para propor tal projeto e discutir a seleção de textos, e, então, começou a nossa colaboração.

No mesmo período que esse texto é escrito, em Julho de 2020, nós acabavamos de saber que a nossa proposta conjunta à FAPESP e o Conselho de Pesquisa Arquitetônica e Humanidades (AHRC), cuja sede é no Reino Unido, para um projeto de três anos e meio, chamado de "Traduzindo Ferro / Transformando Conhecimentos de Arquitetura, Design and Trabalho para a Nova Área de Estudos da Produção (TF/TK)" havia sido bem sucedida. O projeto irá ser inaugurado mais tarde, ainda nesse ano. Em um período em que as condições para os trabalhadores de construção civil estão piorando; design, construção e fabricação de materiais estão cada vez mais mundialmente distribuídos, e a responsabilidade está dividida com sérias consequências para os construtores, habitantes e o meio ambiente, TF/TK propõe que o trabalho de Ferro pode ser aplicado para consolidar uma nova e muito necessária interdisciplinaridade e interculturalidade no campo de Estudos da Produção (EP). O principal objetivo dessa nova área é desafiar a "cegueira" da arquitetura em relação à produção, entendimento e questionamento do design e construção através de contextos culturais. Ademais, segundo Ferro, EP tem como objetivo resistir ao privilégio dos arquitetos em detrimento dos construtores e irá gerar um novo entendimento através da co-produção com criadores de edifícios formais e informais, bem como praticantes de design e acadêmicos, fornecendo apoio conceitual e político para modelos alternativos e novas agências.

O projeto irá envolver uma equipe central liderada por mim, localizada no Reino Unido, e em São Paulo por João Marcos de Almeida Lopes, junto com 4 CoPesquisadores (Silke Kapp, Pedro Arantes, José Lira, Matt Davies) com um time de 16 especialistas afiliados, provenientes de uma gama de disciplinas dentro e além da academia, e cada um irá contribuir com um Estudo de Caso em EP. TF/TK é organizado em volta de três atividades centrais - que são i) coletar dados de pesquisas existentes, por estudiosos e produtores já preocupados com a produção e trabalho em Arquitetura e Design, incluindo a tradução e publicação dos principais trabalhos de Ferro ${ }^{6}$; ii) estruturar o campo do Estudo da Produção usan-

${ }^{6}$ Para incluir a tradução em Inglês de Sérgio Ferro, Dessin/Chantier (Paris: Éditions de la Villette, 2005), a publicação em Inglês e Português do texto de Ferro, Construction of Classical Design, e do o trabalho de Ferro como base e desenvolver os princípios e metodologias de EP com participantes e iii) aplicar e testar os métodos de EP através de 24 estudos de caso, como exemplares para um duplo objetivo: endereçar a lacuna no conhecimento acerca de produção no ambiente acadêmico (histórias de produção informal e formal, relacionadas com abordagens disciplinares, como a Antropologia e Ciências Políticas) e fornecer recursos para ações e mudanças adicionais (documentando o trabalho de movimentos sociais e construtores independentes, registrando as experimentações de formas alternativas da pedagogia do design que se relacionam com a produção). Uma série de eventos públicos no Reino Unido e Brasil começaram quando um website local de EP será inaugurado em 2021 e resultará em uma conferência sobre Estudos da Produção, na Universidade de Newcastle, em 2024.

Nossa confiança é que existirá um forte interesse pelo trabalho de Ferro no contexto da língua inglesa e o reconhecimento de seu valor único em uma comunidade de pesquisadores em expansão, para quem o trabalho e produção foram confirmados como preocupações centrais por eventos mais recentes. Em 2018, Harvard Design Magazine nos abordou para publicar outro texto de Ferro, na edição deles No.46, No Sweat, e financiaram a tradução do texto dele 'Concrete as Weapon' por Kapp e Alice Fiuza. O texto (o qual aparece no meio do livro como um 'encarte' que pode ser removido, como os documentos contratuais que os arquitetos preparam para usar no local de construção, sobre o qual Ferro escreve em Dessin / Chantier) já havia sido bem influente. Em Março de 2019, com o apoio de fundos levantados pelos docentes de Humanidades, Artes and Ciências Sociais (HASS), na Universidade de Newcastle, nós inauguramos 'Concrete as Weapon' com uma semana de eventos em Londres, reunindo pelo menos 70 pessoas, algumas já conhecidas por nós pelo interesse no trabalho de Ferro junto com outros novos participantes. Nós organizamos dois grupos de leitura públicos de 'Concrete as Weapon' e lançamos a publicação no endereço Central St. Martins, com uma introdução ao trabalho de Ferro por Silke Kapp e uma exibição de um documentário sobre a Usina CTAH (2016, 40 mins), com Q\&A (Perguntas e Respostas) de In Between. Quando chegamos no final, nós já havíamos reunido o time e enquadramento para o projeto TF/TK. No dia onze de Outubro de 2019,

uma antologia de textos menores que foram publicados ou não, abordando o alcance da escrita do autor, bem como comentários pelos participantes do projeto. 
uma exibição chamada Dreams Seen Up Close, de curadoria de Davide Sacconi, da Arquitetura Nova e Usina CTAH, abriu na Segunda Biennale d'Architecture d'Orléans ${ }^{7}$. Ferro era o convidado de honra na Biennale e a exibição apresentou muitos elementos de seu arquivo pessoal.

Enquanto o interesse no trabalho de Ferro cresce para além do contexto brasileiro, onde foi desenvolvido pela primeira vez, fica claro que os argumentos dele têm uma audiência internacional, somando-se ao alcance global das suas considerações. Mas, práticas de construção locais são determinadas por múltiplos fatores, que vão desde condições ambientais, sistemas políticos, papéis geopolíticos até avanços tecnológicos, desigualdade social e econômica, tradições de construção e organização do trabalho. Dessa maneira, o campo de EP exige consciência das particularidades e singularidades dos contextos dos locais de produção, que, muitas vezes, são radicalmente diversos. De fato, o próprio conhecimento e ideias de Ferro são esclarecidas por si próprias pelas traduções de conhecimento sobre culturas de construção. Nós estamos ansiosos, acima de tudo, pelas oportunidades de trocas que o TF/TK proporciona, para enfrentar diretamente a tradução e métodos e conceitos em EP, e nos abrir para permitir o aprendizado entre disciplinas e contextos. Mediante $o$ trabalho com os produtores do ambiente de construção, a fim de co-produzir e transformar conhecimento das relações entre design e trabalho de construção, TF/TK procura não só entender e avaliar tais mecanismos criticamente, mas também identificar existentes e possíveis formas de produção, nos quais a construção processa - nelas mesmas e não apenas para seus produtos - pode se tornar como catalisadores para a mudança social, na qual a produção social e material do espaço gera autonomia, igualdade, justiça, criatividade e alegria.

\section{Referências}

ARANTES, Pedro. Reinventing the Building Site. In ANDREOLI, Elisabetta e FORTY, Adrian (orgs.). Brazil's Modern Architecture. London: Phaidon, 2004.

${ }^{7}$ See Biennale website, https://www.frac-centre.fr/ en/biennales/years-solitude/landscapes/dreamsseen-close/dreams-seen-close-1162.html accessed 07.08.2020).
CARVAIS, Robert et al (orgs.). Nuts \& Bolts of Construction History: Vols.1-3. Paris: Picard, 2013.

CONTIER, Felipe. An Introduction to Sérgio Ferro. In LLOYD THOMAS, Katie et al. Industries of Architecture. London: Routledge, 2015.

FERRO, Sérgio. Concrete as Weapon (trad. FIUZA, Alice and KAPP, Silke). Harvard Design Magazine No.4. dez. 2018.

FERRO, Sérgio Ferro. Dessin/Chantier. Paris: Éditions de la Villette, 2005.

FERRO, Sérgio. Dessin/Chantier. An introduction (trad. AGAREZ, Ricardo e KAPP, Silke). In LLOYD THOMAS, Katie et al. Industries of Architecture. London: Routledge, 2015.

LIRA, José T., Architectural Criticism and radicalism in Brazil. In PREISER, Wolfgang F. E. et al.(orgs.). Architecture Beyond Criticism: Expert judgement and performance evaluation. London: Routledge, 2015.

LLOYD THOMAS, Katie et al. Industries of Architecture. London: Routledge, 2015.

MOM (Morar de Outras Maneiras). Architecture as Critical Exercise: Little Pointers Towards Alternative Practices. Field Journal Vol. 2 (1) dez. 2008. Disponível em: http://field-journal.org/wp-content/uploads/2016/07/Architecture-asCritical-Exercise MOM.pdf . Visita em: 29 de agosto de 2020.

WILLIAMS, Richard J. Brazil: Modern architectures in history. London: Reaktion, 2009.

https://www.frac-centre.fr/ en/biennales/years-solitude/landscapes/dreams-seenclose/dreams-seen-close-1162.html. Visita em: 07 de agosto de 2020.

https://www.spatialagency.net/database/sergio.ferro. Visita em: 08 de agosto de 2020. 